\title{
Field performance testing : heritability and correction of sex effect
}

\author{
J. NAVEAU \\ S.C.A., Pen-Ar-Lan, Maxent, B.P. 3, 35380 Plelan-le-Grand \\ France
}

\begin{abstract}
Growth and carcass performances were measured in 9430 animals from the selection centre of Pen-Ar-Lan (France). The sex effect was estimated on the basis of the within litter difference between males and females. Performance heritability was calculated using two models, one including sex, the other excluding it.

Results showed that in a farm unit, sex may be considered as a fixed effect and that a correction may be used in further tests on animals independently of their sex.

The heritabilities obtained $: h^{2}=0.31$ for growth and $h^{2}=0.71$ for muscle content were classical. The difference between males and females was of 6.1 days from 20 to $100 \mathrm{~kg}$ and of $1 \mathrm{p} .100$ muscle in favour of entire males.

Various conclusions may be drawn from these results with regard to the organization of selection schemes in farms.
\end{abstract}

\section{Updating of station selection indices}

\author{
L. OLLIVIER \\ I.N.R.A., Station de Génétique quantitative et appliquée, \\ Domaine de Vilvert, 78350 Jouy-en-Josas
}

France

The data collected from 1969 to 1978 in French test stations were used to devise new selection indices, which have been implemented in these stations since 1981. Four methods of selection were compared on the basis of these data, i.e., boar individual index (ISI), including three performance-test traits, boar progeny index (ISD), including 9 traits measured on 8 daughters, boar sib index (ISS), including 9 traits measured on 2 sisters, and a combined index (ISC), including ISI and ISS traits. Correlations with the aggregate genotype, defined as a linear combination of growth rate, feed efficiency carcass and meat quality traits, were $0.49,0.60,0.71$ and 0.73 , respectively for ISS, ISI, ISC and ISD. These selection indices, although efficient were all expected to produce a negative response in meat quality and even more with ISI than with the other three indices. Restricted ISD and ISS intended to maintain meat quality unchanged were only about 5 percent less efficient than the corresponding indices calculated without considering meat quality. However, when similarly restricted, ISI, was expected to reduce selection efficiency by 54 percent. This points to the need to find an in vivo predictor of meat quality which could be included in the boar individual index. 